\title{
Aproximación histórica ao galego nas escolas (1900-1936): un saber ausente e unha voz silenciada
}

\author{
Sabela Rivas Barrós \\ Universidade da Coruña
}

\section{Introdución}

"De pé... e despois chamábanos un por un e dicía que señalaramos co punzón, porque claro, nós cantabamos todo o que sabiamos onde estaba, e no mapa, e esto... liamos, non sabes? E cando liamos e cando diciámo-las cousas, pois diciámolas en castellano, como estaba alí escrito... nós liamos como estaba escrito, que nós en galego non". Estas son as palabras de que se vale Carme, de 67 anos, para describir unha xornada da súa infancia nunha escola de Ribeira, e que nos van servir de mostra para nos mergullarmos no tema do noso traballo.

Quizais nos resulte coñecido o tacto dun punteiro de madeira nas mans que percorre o mapa de España sinalando as provincias, os ríos e os seus afluentes, as cordilleiras e as capitais acompañado dun ton musical que favorecía a aprendizaxe memorística que o mestre ou a mestra pretendía. Con todo, no fondo deste "lirismo" acochábase unha realidade moito máis triste que Carme intenta suavizar cando fala con naturalidade das dificultades, explícitas ou implícitas, de empregar o galego, a lingua habitual da maior parte da poboación, nas actividades pedagóxicas.

As vivencias de Carme e de moitas outras persoas' que nos relataron a súa historia da vida escolar servíronnos de alicerce para levar a cabo un estudio sobre a práctica lingüística nas escolas galegas a partir do ano 1900 ata a chegada da II República.

Nas páxinas que seguen faremos mención, en primeiro lugar, á evolución da política e lexislación educativa en que aparecen reflectidas unha serie de

Agradecemos a colaboración na realización das entrevistas ao alumnado da materia "Historia da Educación Infantil" da Facultade de Ciencias da Educación da Universidade da Coruña e mais a todas aquelas persoas que compartiron connosco o recordo da súa infancia. 
disposicións, decretos e leis que recollen as medidas que regulan o uso do galego e do castelán nas escolas. En segundo lugar, analízase a práctica linguuística nos centros educativos, que, en moitas ocasións, non responden á lexislación vixente nese momento. Por último, farase unha análise das accións de carácter diferencialista que van incidir na galeguización do ensino.

\section{Evolución lexislativa}

Aínda que cómpre ter en conta que a política de uniformismo lingüístico se emprendeu xa desde o final da época medieval, será no século XIX cando se asiste á definitiva nacionalización dos estados. Estes pasan a ser a expresión política das nacións, polo que se intenta incrementar a súa influencia na vida da cidadanía a través das institucións mediadoras que posibilitarán a construción ou reconstrución das identidades nacionais a partir das tradicións culturais preexistentes, outorgándolle un papel predominante na súa difusión ao sistema educativo. Deste xeito, e dado que un dos elementos centrais de toda a cultura nacional é o constituído pola lingua, emprenderase un proceso de uniformismo linguístico dirixido á estandarización das linguas e á conseguinte imposición dos idiomas estato-nacionais, que, no caso de Galiza, significará un intento de asimilación do galego por parte do castelán, considerado polo Estado o idioma nacional.

En definitiva, como precisaron diversas autoridades sobre o tema ${ }^{2}$, o proceso de construción e afianzamento do estado liberal español desencadeará a homoxeinización política, cultural e lingüística da poboación, ignorando a pluralidade cultural e o diferencialismo lingüístico dos pobos englobados no Estado; neste sentido, podemos afirmar que ao longo de todo o século XIX, á medida que o Estado se dota de novas institucións e amplía o seu poder, acrecéntanse as disposicións impositivas do castelán e prohibitivas co uso de calquera outra lingua: disposicións relativas a medidas pedagóxicas para a erradicación da lingua nativa do alumnado, escrituras notariais e usos litúrxicos, entre outras.

A primeira lei de educación, a Lei Moyano de $1857^{3}$, decreta o ensino primario como obrigatorio e regula o estudio do castelán propondo como texto único a Gramática e Ortografía da Real Academia Española. O cambio de século coñecerá, dentro do fracaso da Restauración e cunha inxección centralista reforzada despois do "desastre do noventa e oito", un reforzo das leis prohibitivas no que se refire ao emprego doutras linguas distintas do castelán. Neste sentido resulta ilustrativo o

\footnotetext{
2 Véxanse os completos traballos de Garcia Negro (1991), Mariño Paz (1998) e Monteagudo (1999).

Véxase o estudio de Puelles Benítez (1986).
} 
aviso de Eduardo Dato, ministro de Gobernación en 1900, a o considerar que o seu goberno debe intensificar a acción uniformadora emprendida por gobernos anteriores, posto que non se podía dar por definitiva a desaparición das linguas non hexemónicas. Reproducimos a súas palabras:

Es sensible que no todos los españoles conozcan el idioma nacional; pero es un hecho innegable respecto al cual no cabe más que una constante propaganda encaminada a extender el conocimiento de la lengua oficial, evitando que en las escuelas del Estado se enseñe otro idioma que el español, no permitiendo textos escritos en ningún dialecto, como libros de enseñanza, y adaptándose por las autoridades las medidas que se han adoptado al efecto, y que aplicará este Gobierno como las han aplicado todos los anteriores gobiernos de España (Ferrer 1986: 85).

Seis meses despois da subida ao trono de Alfonso XIII, no mes de novembro de 1902, promúlgase un Real Decreto en que de maneira taxativa se impón a obrigatoriedade de usar o castelán para explicar a Relixión ou calquera outra materia, xa que foron moitas a denuncias formuladas por inspectores provinciais de ensino primario que evidencian o emprego do galego nalgunhas escolas.

Por iso, o artigo do Real Decreto establece medidas punitivas concretas:

Los Maestros y Maestras de instrucción primaria que enseñasen á sus discípulos la doctrina cristiana ó el dialecto que no sea la lengua castellana, serán castigados por primera vez con amonestación por parte del Inspector provincial de primera enseñanza quien dará cuenta del hecho al ministro del ramo; y si reincidiesen, después de haber sufrido una amonestación, serán separados del magisterio oficial, perdiendo cuentos derechos le reconoce la ley (Costa Rico 1989: 68).

A Ditadura de Primo de Rivera continúa con esta mesma política: o profesorado deberá falar aos nenos e ás nenas sempre en castelán, as materias comprendidas no plano oficial deberán ser impartidas en castelán, aínda que as complementarias poderán darse en "idiomas rexionais". Propóñense sancións efectivas para o profesorado que non cumpra con este mandato, unha delas o desterro a "otras provincias en que no existan formas idiomáticas distintas del lenguaje oficial", ou a apertura de expediente a aqueles que "proscriban, abandonen o entorpezcan la enseñanza en su escuela del idioma oficial en aquellas regiones en que se conserva otra lengua nativa".

Finalmente, o período 1931-1936 vai supor unha etapa favorable na recuperación das institucións galegas e un avance fundamental na extensión do idioma e da cultura galega. Así, a partir de 1932 o goberno da República publica dous Decretos en que se declaraba a legalidade do bilingüismo en Cataluña, ao tempo que se recoñecía a existencia dentro do Estado español doutras linguas ademais do catalán: o galego e o vasco. Porén, a tardanza do plebiscito do Estatuto de 
Autonomía en que se recoñecía a cooficialidade do galego e do castelán impediu a posibilidade da súa aplicación, pois poucos días despois comezou a Guerra Civil, que significou o principio dun longo período de "ilexitimade" doutras linguas que non fosen o castelán.

\section{A práctica lingüística nas escolas}

Nun estudio que estamos a realizar, en que se empregan fundamentalmente fontes orais, unha das cuestións a que se fai referencia é ao uso que se facía do galego nas escolas. Aínda que excede os límites de espazo deste artigo a referencia a todos os aspectos analizados, sinalamos algunhas conclusións. En primeiro lugar, indicamos que nas escolas galegas se daban principalmente tres tipos de situacións con respecto ao uso da lingua galega: entre os nenos e nenas falábase case exclusivamente o galego e castelán co profesorado; o alumnado falaba entre si en galego e tamén co profesorado; e, por último, o profesorado utilizaba o galego como instrumento didáctico para favorecer a aprendizaxe dalgún termo castelán.

A situación sinalada en primeiro lugar era a que provocaba un maior conflito, posto que os nenos e nenas tiñan un escaso, cando non nulo, coñecemento do castelán. Así o recoñece Lourdes, de 62 anos: “...bueno, ao principio non, pero despois si, entendiámolo e cuidabamos de non fala-lo galego na escola, sobre todo que non nos escoitara a mestra".

Nestes casos era, como indican a maioría dos nosos informantes, cando se recorría en moitas ocasións aos castigos para evitar o emprego do galego nas aulas. En palabras de Ramiro, de 84 anos: "Naquel tempo, loxicamente era o galego, na casa, na aldea, en tódolos sitios, pero na escola era o castellano, e se falabamos o galego na escola castigábannos". Outra informante, Josefa, de 77 anos, fai unha precisión respecto a este tema: " $\mathrm{Si}$, deixaban falar o galego entre nós. Antes si, pero despois había que falar o castelán nos colexios porque Franco non quería que falásemos galego, tíñamos que falar castelán”. Tamén María, de 66 anos, indica a existencia de castigos nas escolas por falar o galego, pero tamén engade comentarios que nos indican o pouco prestixio social que tiña esta lingua en oposición ao castelán e que se reflectía tamén no ámbito familiar. Estas son as súas palabras: "Pois na escola o castelán, falábase todo, porque non nos deixaban falar en galego porque estaba prohibido, era... era xa de anos. E na casa normalmente falabamos en galego, pero...cando por exemplo falabas en galego fóra da casa, cos teus pais diante, miña nai dicíame: 'non fales en galego, fala en castellano que é de aldeán falar en galego",.

Con todo, segundo indica Narciso de Gabriel (1990: 160-172), o uso exclusivo do 
castelán nas escolas decimonónicas batía con importantes obstáculos, xa que a maior parte dos mestres e mestras tiñan o galego como lingua de instalación e algúns posuían só un coñecemento rudimentario do castelán, que se acentuaba entre os mestres incompletos que dispuñan dunha formación pedagóxica e cultural moi precaria.

As dificultades dos mestres e mestras para se expresaren en castelán acrecentábanse no caso dos nenos e nenas que tiñan como lingua habitual o galego e que descoñecían practicamente o castelán. Ante este feito podemos tirar en conclusión que tamén dentro do recinto escolar se empregaba decote o idioma galego, aínda que ás veces respondesen ás preguntas do profesorado en castelán.

Nas escolas do primeiro tercio do século XX reprodúcese a mesma situación que nas escolas decimonónicas: aínda que, como sinalamos en páxinas anteriores, a lexislación impedía a utilización do galego, en moitos casos tanto o alumnado como o profesorado tiña serias dificultades para se expresar en castelán. Así nolo confirma Carme, de 65 anos: "Falabamos o castellano conforme se sabía, que non se sabía moi ben tampouco. Os mestres tamén conforme sabían, porque ao fin era galego, e eles tamén eran galegos"; e tamén Francisco, de 84 anos: "Namais entrar da porta da escola pra dentro todo en castelán, había personas que era un descojono ó́las pero non había máis remedio".

Esa inseguridade lingüística que tan ben nos describe Francisco era froito da interiorización dunha aprendizaxe non sempre explícita: falar galego era falar mal e falar castelán era falar ben e, posto que a escola non lograra implantar o coñecemento e uso do castelán, en moitos casos a mellor alternativa para o alumnado era o silencio como o demostran numerosos informes da Inspección e comentarios do profesorado en que se destaca o silencio dos nenos e das nenas ante as preguntas dos inspectores e do propio profesorado. Eis un testemuños:

Los niños oriundos de lengua y raza celta, temen hablar el castellano, ante el profesor que interroga, y prefieren pasar por irreverentes y anormales, antes que su lengua se abra para dar el nombre al signo, no por la ignorancia e incomprensión del objeto nombrado, sino por ese temor a hablarlo (Fernández 1928: 3).

E se de signos falamos temos de abordar un aspecto fonético que foi obxecto de burlas e de castigos nas escolas galegas. Trátase da "gheada" e "gueada", xa que unha das grandes teimas dos mestres e mestras así como dos inspectores consistía en acabaren coa gheada aọ ser considerada como un signo de "rusticidade" e "incultura", desprezado e atacado tamén por gramáticos, lexicógrafos e outros estudiosos, como é o caso de Valladares no ano 1884 no prólogo do seu Diccionario Gallego-Castellano, onde se indica: "Las geadas 
son un defecto de la gente idiota: consisten en hacer fuerte la $g$ suave, como gaita, guerra, guinda, gozo, gusto..." (citado en Fernández Rei 1991: 177); na mesma liña fala Cotarelo Valledor: "tan grosero hábito sólo se usa entre el vulgo, pero a veces induce a confusión a personas algo ilustradas" (citado en Fernández Rei 1991: 178).

Non obstante, aínda que escasos, esta pronuncia tamén tiña defensores, como é o caso dun dos grandes partidarios do emprego do galego no ensino, Aurelio Ribalta, de quen reproducimos parte dun texto escrito en 1910:

Eu sigo a prenunzia das mais das xentes de Galicia, non tan forte koma de $\mathrm{j}$ frikativa, simple, trinada, nin tanpouco ko a sonoridá do g glótico, o g duro do francés..

Boume koo feito filolóxiko, pouko estudiado aínda, e ben mais merezente destudio ke dos kalifikatib "defecto de gente idiota", "abuso de simple pronunciación” e outros polo estilo (citado en Fernández Rei 1991: 180).

Mais o profesorado coincidía máis coa opinión de Valladares e Cotarelo que coa de Ribalta, como demostra De Sergude nas páxinas de A Nosa Terra no ano 1916 :

E tanto traballa o mestre ensinándolles o ja, jo, ju, ge, gi, co sentido castelán, que xa, no diante, non hai para os probes neniños nin regatos, nin fragas e demais verbas que teñen algún $g$, inda que este sino endexamais tuvo na nosa fala a pronuncia áspre que se lle dá ao j no idioma de Castela (Sergude 1916).

Aínda case vinte anos despois, en 1935, parece que a tarefa do mestre non rematara, pois desde o xornal La Voz de Galicia continuábase a insistir no mesmo tema:

La labor del maestro al frente desta escuela ha de empezar, incluso en los niños de 14 años, por enseñarles a hablar. Hay que luchar denodadamente para conseguir que digan "Galicia" en vez de "Jalicia" (Sueiro 1935).

En conclusión, canto á práctica lingüística nas escolas rurais galegas, na etapa que nos ocupa, podemos indicar que a utilización do galego ou do castelán polo profesorado non era uniforme nen singular, senón que, dependendo da titularidade das escolas, do lugar de emprazamento, da actitude dos pais e nais e das presións exercidas pola inspección, o emprego dun ou doutro idioma nas relacións propiamente educativas era variable. En consecuencia, aínda que o ensino primario non posibilitaba máis que un dominio rudimentario do castelán, os nenos e nenas realizaban unha aprendizaxe moi significativa ao seu paso pola escola: falar castelán era falar ben e falar galego era falar mal. Polo tanto, e ante caso de dúbida, o mellor era o silencio. 


\section{As reivindicacións galeguizadoras}

Como xa indicamos noutro lugar deste traballo, o sistema educativo vai ser un dos medios máis importantes na difusión das identidades nacionais e, máis concretamente, das culturas nacionais. De aí que unha das accións de carácter diferencialista a que se vai dedicar un maior esforzo sexa a galeguización do ensino e, no tema que nos ocupa, a reivindicación do estudio e utilización do galego nos distintos niveis educativos.

Así o fixo Frei Martín Sarmiento no século XVIII ao iniciar o discurso pedagóxico a favor da utilización do galego nas escolas. No seu pensamento pedagóxico, Sarmiento decídese por unha educación realista e empirista, concedéndolle o máximo protagonismo educativo ao alumnado; de aí que se preocupe por unha aprendizaxe gradual partindo dos coñecementos máis próximos aos escolares. Postula a posta en práctica de diversos recursos didácticos e metodolóxicos, rexeitando os métodos tradicionais autoritarios e memorísticos. Preocúpase tamén pola educación familiar infantil, tratando nos seus escritos temas como a crianza con leite materno, a situación das amas de cría, os xogos e a educación moral na familia, entre outros.

Seguindo as ideas ilustradas, reclama o desenvolvemento científico, social e económico da sociedade ampliando as súas arelas ao estudio das ciencias naturais, aos avances científico e técnico, ás matemáticas e ao estudio do medio xeográfico.

Por outra parte, as súas reflexións convertéronno no precursor das reivindicacións da galeguización do ensino a través do demandado uso e estudio da lingua galega nas escolas, da proposta de edición de textos en galego e a creación de cátedras de lingua galega, á parte da defensa do uso do galego na liturxia. A decidida defensa da escolarización en galego faina deste xeito:

Es una desalmada necedad poner a los niños gallegos a la xerga de la Gramática, antes de saber, con mucha extensión, la lengua gallega; y todas las voces de la Historia natural, a lo menos de las visibles de su país. Hazte cargo que al portugués se le enseña el latín en portugués. Al francés en francés. Al italiano en italiano. Al inglés en inglés. Al sueco en sueco. Al castellano, solo en castellano. Pues, ¿Qué fatuidad es que al niño gallego se le enseñe una lengua innota en lengua castellana que no entiende? Avía de quemar todo libro de Gramática, que pasase por Galicia, y que no estuviese explicado en lengua gallega [...] (Pensado 1984: 147-151).

Xa no século XIX, iníciase desde posicións Rexionalistas unha campaña en defensa da inclusión do galego como materia de estudio nas escolas. Era esta unha campaña de carácter conservacionista, xa que se defendía o emprego do galego nos espazos ata ese momento reservados para el (folclore, poesía), mais sen entorpecer 
os dominios do castelán, que gozaba de espazos máis estendidos (cultos relixiosos, administración, xustiza investigacións científicas, etc.).

Nesta etapa podemos destacar a edición no ano 1859 do libro de lectura escrito por Manuel Murguía La primera luz. Trátase dun libro concibido como cartilla escolar que consta de 64 páxinas en que se introducen diferentes tipos, estilos e tamaño de letras. Escrito en castelán, segue a nota dominante da época se nos atemos aos datos aportados por Costa Rico (1997) que establece nun $4 \%$ os materiais didácticos escritos en galego dun total de 350 documentos impresos sobre temática educativa en Galiza no período de 1766 a 1936. Este dato pode resultar cando menos curioso se temos en conta que nesta época predominaba o uso oral do galego en máis do $90 \%$ da población, o que demostra o afastamento entre o mundo escolar e a realidade social e cultural que a rodea.

O profesor Peña Saavedra indica que La Primera Luz se trata dun libro de lectura para as escolas polo que estaría baixo o control da lexislación, que, como xa indicamos, era totalmente contraria á utilización da lingua galega nas escolas (Peña Saavedra 2000).

A primeira lección desta cartilla escolar diríxese ao alumnado co fin de evitar a burla de aqueles nenos e nenas que falan o galego:

Hijos mios ¿cúal es la falta de ese inocente para que os burleis de él? No sabe castellano, y habla en el dulce lenguaje de su tierra nativa, en el lenguaje en que hablaron sus abuelos! Sabed niños que el dialecto gallego, cuyas armoniosas palabras excitan vuestra risa, como si fuerais extraños, es la fuente de donde salió el idioma español (Peña Saavedra 2000: 12).

Outro momento destacable na defensa do uso do galego nas escolas corresponde co discurso lido polo mestre José Soto Campos no Congreso Pedagóxico celebrado en Barcelona no mes de agosto de 1888 como contribución á sección que levaba por título "En las provincias del Norte y del Este de España, donde no es nativa la lengua castellana, ¿qué procedimientos deben emplearse para enseñarla a los niños?". Aínda que por imperativo legal non se explicitase no título da reunión, en realidade o obxectivo que se perseguía era a reivindicación da incorporación dos idiomas catalán, vasco e galego ás escolas.

Así o fai Soto Campos (1889) cando defende que nas nosas escolas se ensinase simultaneamente o galego e o castelán, argumentando que cando os mestres permitían o emprego do galego, o alumnado aprendía mellor o castelán que naquelas en que se prohibía. Para este mestre, a convivencia das linguas sería posible cando se recoñecesen as unidades naturais e a variedade dentro destas unidades naturais, en clara oposición ás unidades ficticias que van en contra da natureza das cousas, posto que, en opinión do relator, a unidade dunha patria non 
se soluciona por medio dun decreto, senón permitindo o uso da lingua propia de cada pobo.

En definitiva, Soto Campos foi un dos primeiros mestres que defendeu publicamente a incorporación da lingua galega á escola a pesar das críticas que recibiu de boa parte do maxisterio, que era maiormente contrario ao estudio e emprego do galego como lingua vehicular no ensino.

Un ano despois, Alfredo Brañas (1884) publicará a súa obra El Regionalismo en que se reflicten as súas ideas sobre o tema educativo, sinalando o ensino como un dos elementos diferenciadores (xunto coa lingua os costumes e a literatura, entre outros) da Rexión. Así, dentro da súa organización propón a creación de seis Secretarías das cales unha delas correspondería á Instrución e contaría coas seguintes seccións: De ensino superior: Universidade, Escolas Especiais e Academias, de Segundo Ensino ou Institutos, Colexios preparatorios e de Primeiro Ensino.

En cada Rexión podería haber unha Universidade oficial pagada con fondos da mesma Rexión. Cada unha contaría con oito Facultades. A instrución primaria debería ser obrigatoria e gratuíta, dividíndose as escolas en Elementais e Superiores. En todas elas defende Brañas o estudio da lingua galega:

lo que más caracteriza y personifica a un territorio determinado, son las tradiciones, las costumbres, la historia y el lenguaje. Por esto en primer término, ha de cuidar la Dieta regional de que se estudie en las escuelas de instrucción primaria el idioma primitivo, que en la vida doméstica y familiar alterna con el idioma común o nacional (Brañas 1889: 112).

A partir de 1916, o galeguismo comeza e estender tanto cuantitativa como cualitativamente as reivindicacións sobre o idioma galego. Neste momento, empréndese unha liña de normalización que se vai traducir no uso, exhibición, dignificación e ampliación do volume e presenza pública do galego. Esta liña de normalización vai superar con clareza as anteriores reivindicacións que demandaban a introdución do galego como materia de estudio. Agora vaise pedir, principalmente a partir de 1932, o uso do galego como vehículo de comunicación no proceso de ensino-aprendizaxe.

Sen dúbida, estas reivindicacións non eran só un problema de linguaxe; estaba en xogo a toma de consciencia da realidade nacional de Galiza, con todas as súas posibilidades, simbolizadas na cuestión lingüística, xa que a aceptación do feito de que o uso do galego e do castelán non é só unha asunción individual, senón que está determinado social e politicamente, leva os galeguistas a criticaren duramente a unificación lingüística que se está levando a cabo a través dunha política centralista, pois para eles a lingua é o elemento distintivo máis importante dun pobo. 
Así pois, a morte ou agonía dunha lingua vai facer que o pobo que a fala desapareza como tal, pois renunciar a unha lingua significa renunciar á existencia como nacionalidade. E, precisamente, ao que non está disposto o galeguismo é a renunciar ao seu obxectivo principal que era, como xa sinalamos, conseguir o recoñecemento de Galiza como nación; deste xeito van intentar por todos os medios acabar coa política asimilista que está utilizando a escola como elemento desgaleguizador, prohibindo que nela se fale e estudie o galego.

Esta prohibición era moi preocupante, pero aínda preocupa moito máis a mensaxe, non sempre subliminal, que se transmitía nas escolas: o galego é unha lingua "rústica" e "inculta" moi inferior ao castelán. Esta mesma mensaxe tránsmitíase non só nas escolas senón tamén na vida cotiá dos falantes galegos, como o reflicte o noso informante Antonio de, 78 anos: "Eu falei sempre o galego, muller, mal falado, porque non nolo ensinaron doutra maneira. Con todos. Eu falaba o galego con todos. E iba a "La Coruña" e ríanse de min pero eu falaba o gallego o mismo".

Castelao foi un dos intelectuais galeguistas que impulsou o debate sociolingüístico na primeira metade do século XX. Neste sentido, fai unha análise profunda do problema cando indica:

o neno galego que vai â escola fala unha lingua diferente, pero semellante â do mestre: unha língoa que non é dos libros nin das cartas que se reciben na súa casa. $\mathrm{O}$ neno esforzase en falar na língoa do mestre, que considera superior â que falan os seus pais. O neno deprende a decir moitas cousas sen saber ben o que dí e sen comprender ben o significado das verbas que pronuncia. A interferencia das duas língoas rebaixa o desenrolo espritual do neno, porque non sabe falar a lingoa do mestre e ten vergonza de falar na língoa que mamou (Castelao 1976: 339).

Con estas reflexións Castelao está a describir a disfuncionalidade existente entre as dúas linguas. O emprego dunha ou doutra non vai ser indiferente socialmente. Da consciencia de falar peor do que os demais grupos (ou falar mal) nace a inseguridade lingüística. Esa extorsión non é espontánea porque os valores superiores atribuídos a unha fala nacen do grupo de máis poder da comunidade lingüística.

A análise desta situación diglósica en que vivía o galego convenceu os galeguistas de que para conseguiren o seu obxectivo de incorporalo como lingua vehicular no proceso de ensino-aprendizaxe debían intentar modificar a súa consideración social e, dado que o prestixio do galego se debía á presenza doutro idioma que detentaba o poder e a que se concedían todas as virtudes que a aquel se lle negaban, a tarefa principal consistía en proporcionar argumentos que contribuísen ao seu aprecio e que o colocasen na práctica á par do castelán. Estes argumentos podémolos resumir en factores de identificación, de utilidade e de prestixio (Hermida 1992: 90-142).

Os factores de identificación inclúen todas as argumentacións que buscaban o cambio de actitude dos falantes con respecto ao seu idioma, revelándolles o 
significado que tiña para o pobo como colectivo identificado polo uso dunha lingua diferenciada. Xohán Vicente Viqueira foi un dos primeiros pedagogos do primeiro tercio do século XX que defendeu o emprego do galego nas escolas aducindo argumentos de identificación. Declaraba ao respecto:

\begin{abstract}
A língua é un anaco da nosa alma coleitiva do que ninguna lei humana poderá obrigar a desprendernos [...] a división lingüística trai consigo unha división cultural perigosa para Galicia. Cinco sestas partes d'os galegos falan galego e sô unha sesta parte castelao, ou millor, unha cousa que máis das veces sômente con aproximación pode chamarse castelao. Entre as dúas clas de poboación linguiística esiste unha división fondísima, cuase un abismo, que é preciso desfacer. E isto non pode abranguerse prácticamente mais que falando o galego, a sesta parte da poboación queé a que representa a cultura superior ou, ao menos, pretende e pode representala (Viqueira 1974: 148).
\end{abstract}

Os factores de utilidade abranguen todos os argumentos que demostran o beneficioso e útil que era para o ensino a introdución do galego como código de comunicación aducindo as seguintes razóns: en primeiro lugar, coa obrigatoriedade do uso do castelán nas escolas non se consegue que o alumnado aprenda este idioma, xa que os mestres e mestras, principalmente os incompletos, non teñen o desexable dominio desta lingua nen a suficiencia pedagóxica que lles permita levaren a bo fin o seu ensino, razón pola cal os nenos e nenas saen das escolas sen saberen falar, ler ou escribir o castelán nen o galego. Victoriano Taibo descríbenos este feito:

nas nosas escolas onde os escolantes se empeñan n-enseñaren o castelao pol-o castelao mesmo, os probes cativiños san d'ilas fartos de labazadas e valdeiros de letras (Taibo 1917).

En segundo lugar, dado que a principal misión do profesorado é a de se comunicar co alumnado, achegarse ás súas inquedanzas, coñecer os seus problemas, transmitirlle e recibir coñecementos, cómprelles aos docentes evitar todo o tipo de interferencias, entre elas a de non empregar o mesmo código verbal.

Por último, nos factores de prestixio temos de indicar que na busca de apoios científicos que defendan o emprego do galego nas escolas recórrese en moitas ocasións a autores da Escola Nova, como por exemplo a Decroly ou Pestalozzi, coñecidos polos seus estudios sobre o emprego do ensino da lingua materna. Así o fai Antón Villar Ponte cando escribe:

Pestalozzi dijera que hay una sola escuela buena: aquella que imita a su madre. Y una escuela donde el maestro no sólo trata de enseñarles a los párvulos en idioma diferente del que ellos usan sinó que les reprende incluso cada vez que exteriorizan alguna palabra del propio, ¿cómo ha de atraerlos en ningún caso? (Villar Ponte 1935). 
Por outra parte, tamén Vicente Risco no seu "Plan pr'a Galeguización d'as Escolas" vai adicar un apartado especial ao tema da lingua, recollendo todos os argumentos para defender a entrada do galego na vida escolar e expondo esquematicamente a metodoloxía didáctica para empregar no seu estudio, sempre facendo fincapé na alternancia do galego co castelán.

Con todo, non falta quen, desde o galeguismo, defenda posturas monolingües canto ao emprego do galego no ensino. Tal é o caso de Rogelio Pérez "Roxerius" que, aínda admitindo que o bilinguísmo é quizais a demanda máis realista, pensa que a solución ao conflito pasaría pola obrigatoriedade de o empregar en todos os niveis do ensino:

nos, referíndonos o galego, que é un idioma e non un dialeuto, chegaríamos cicais a decir para todo o ensino. Pro quedémos n'o bilingüísmo, indo a él dendes d'o galego (Roxerius 1934).

Por último, cabe mencionar a crítica que desde o galeguismo se facía ao profesorado foráneo por estar a impartir nas escolas rurais de Galiza sen coñecer a lingua nen a cultura galega. Para estes mestres e mestras propúñase a asistencia obrigatoria a cursos especiais sobre cultura galega en que deberían, ao rematar os mesmos, conseguir un certificado de aptitude.

Para o profesorado galego iniciouse un labor de conscienciación insistindo constantemente na necesidade da utilización do galego nas escolas. Para conseguir este obxectivo, vaise realizar unha campaña a favor da creación de cátedras de Galego nas Escolas Normais, así como a inclusións nos seus planos de estudio de materias relacionadas coa cultura galega.

En resumo, podemos concluír que na práctica escolar das escolas decimonómicas e do primeiro tercio do século $\mathrm{XX}$ se evidencia que o emprego do galego ultrapasaba en moitas ocasións os límites que establecía a lexislación vixente, aínda que, en moitas outras, os castigos por non falar o castelán eran frecuentes. Este feito leva ao galeguismo a emprender unha serie de accións encamiñadas á recuperación normalizadora do idioma galego, entre as que se incluíu un importante labor de conscienciación política entre o profesorado.

\section{Referencias bibliográficas}

Brañas, A. (1889): El Regionalismo (Barcelona: Jaime Molinas Editor).

Costa Rico, A. (1989): Escolas e mestres. A Educación en Galicia da Restauración á Segunda República (Santiago: Xunta de Galicia).

Costa Rico, A. (1997): "El libro escolar en gallego", en Escolano Benito, A. (dir.): Historia ilustrada del libro escolar en España. Del Antiguo Régimen a la Segunda República (Madrid: Fundación Sánchez Ruipérez). 
De Gabriel Fernández, N. (1990): Leer, escribir y contar: Escolarización popular y Sociedad en Galicia (1875-1900) (Sada: Ediciós do Castro).

Fernández, L. (1928): "La Pedagogía moderna y la escuela de aldea”, Vida escolar (610-1928).

Fernández Rei, F. (1991)[1990]: Dialectoloxía da lingua galega (Vigo: Xerais).

Ferrer i Girones F. (1986): La persecució política de la llengua catalana (Barcelona: Edicions 62).

Garcia Negro, P. (1991): O Galego e as Leis. Aproximación sociolingüística (Vilaboa / Pontevedra: Ed. Do Cumio) .

Hermida, C. (1992): Os precursores da normalización. Defensa e reivindicación da lingua galega no Rexurdimento (1840-1891) (Vigo: Xerais).

Mariño Paz, R. (1998): Historia da lingua galega (Santiago: Sotelo Blanco).

Monteagudo, H. (1999): Historia social da lingua galega. Idioma, sociedade e cultura a través do tempo (Vigo: Galaxia).

Murguía, M. (1996) [reimpr. facs.da de 1859]: La Primera Luz. Estudio Introductorio de Peña Saavedra, V. / Fernández González, M. (Santiago: Xunta de Galicia).

Pensado, J. L. (1984): La educación de la juventud de Fray Martín Sarmiento. Edición y estudio crítico (Santiago: Xunta de Galicia).

Puelles Benítez, M. (1986): Educación e ideología en la España contemporánea (Barcelona: Labor).

Rodríguez Castelao, A. D (1976) [1944]: Sempre en Galiza (Madrid: Akal).

Roxerius [Rogelio Pérez] (1934): “A Pedagoxía y-o bilingüísmo”, El Pueblo Gallego (25-7-1934).

Sergude, L. de (1916): "Pol-as Escolas Galegas”, A Nosa Terra (25-12-1916).

Soto Campos, J. (1898): “En las provincias del Norte y del Este de España, donde no es nativa la lengua castellana, ¿qué procedientos deben emplearse para enseñarla a los niños" [discurso lido no Congreso Nacional Pedagógico] (Barcelona: Tipografía de la Casa de la Caridad).

Sueiro, J. (1935): “Realidad de la Escuela rural”, La Voz de Galicia (16-2-1935).

Taibo, V. (1917): “A fala no enseño”, A Nosa Terra (5-1-1917).

Villar Ponte, A. (1935): "El serio problema del bilingüismo en la escuela", La Voz de Galicia (23-1-1935).

Viqueira, X. V. (1974): Ensayos e poesías (Vigo: Galaxia). 